\title{
A Development of Systematic Learning Resources Management Process to Strengthen Sufficiency Attributes of Secondary School Students
}

\author{
Samrit Kangpheng ${ }^{1}$, Sarayuth Kunlong ${ }^{2}$, Supot Mityodwong ${ }^{2}$, Peerapet Sirikul ${ }^{2} \&$ Chutipa Buddeevong $^{2}$ \\ ${ }^{1}$ Nong Kung Wittayakarn School, Khon Kaen, Thailand \\ ${ }^{2}$ Faculty of Political Science and Public Administration, Rajabhat Mahasarakham University, Thailand \\ Correspondence: Samrit Kangpheng, Nong Kung Wittayakarn School, Thailand. Tel: 668-8560-6666. E-mail: \\ skangpheng@gmail.com
}

Received: July 13, 2018

Accepted: September 18, 2018

Online Published: November 27, 2018

doi:10.5539/ies.v11n12p42

URL: https://doi.org/10.5539/ies.v11n12p42

\begin{abstract}
The research objective was to develop and evaluate systematic learning resources management process in inputs, process, outputs, outcome, and feedback of Nong Kung Wittayakarn School in Thailand. Research participants and key informants were 5 Grade 7-9 teachers, 34 Grade 7-9 students, 34 student parents, and 9 school board members totaling 82 people. Research tools were survey form, semi-structured interview form, learning resources evaluation form, sufficiency-oriented life satisfaction evaluation form, and meeting record form. The data analysis employed frequency, percentage, mean, standard deviation statistics and content analysis. Research findings reveal that systematic learning resources management process to strengthen sufficiency attributes of secondary school students comprises 1) Inputs - internal staff, external people, and supporting budget; 2) Process-Define, Create, Capture, Share, and Use; 3) Outputs - overall learning resources evaluation had 3.33 average from the 4-point scale with people at highest level followed in descending order by economic, societal, environmental and cultural domains; 4) Outcome - overall and detailed sufficiency-oriented life satisfaction evaluation are at high level with psychological dimension at the highest score followed in descending order by well-being sustainability - self-reliance, immunity, and resilience; and 5) Feedback with reflection cycle-before action review (BAR), during action review (DAR), and after action review (AAR). The evaluation of the process reveals that the participants' acceptance is at highest level.
\end{abstract}

Keywords: knowledge management, systematic learning resources, development

\section{Introduction}

\subsection{Rationale}

The world sees sudden changes at present on economics, culture, society, politics and governance. Especially the influence from scientific and technological progress is accelerating factors for borderless world. Information are circulating in positive and negative ways with increasing complexity and disruption. Those above factors impact tremendously on individual's way of life causing myriad problems. The ideas behind Standardized National Education Administration and Second Decade of Educational Reform (BE 2551-2561) were designed to solve the problems by designating quality long-life education and learning society for Thailand. This plan of long-life education for all will foster quality of life and integration among wisdom, ethics, and culture. All society's stakeholders have their part to engage in educational management according to the needs of students and local context (Local Administration Organization, Northwestern Provinces Group, 2014). However, the previous $20^{\text {th }}$ Century educational administration focused on knowledge transfer from teacher to student, but the $21^{\text {st }}$ Century viewed learning as co-creation of knowledge among teachers, students, and stakeholders. The major role of school now is to learn and interact with the community that becomes social laboratory for knowledge creation and collaborative learning. The communities altogether become knowledge-based society and economy in touch with the present world.

Each society must seek capacity to apply knowledge into innovation as the tool for driving social progress. The knowledge and innovation effect changes in paradigm shift for Thai society in order to survive all around pressures especially globalization with the model of "Triangle Moving Mountain" comprising three factors-social 
movement, knowledge, and policy link. The model can systematically support structural changes in laws and regulations. The hardest factor to gain for this change is therefore knowledge (Panich, 2015).

Since education is the heart of human capital development to become valuable resource with desirable characteristics to live happily in society, the education reform mentioned above aims education as significant tool for human and social development. The desirable characteristics of future Thai citizens are visionary, foresighted, goodness oriented, ethical, and resilient against world changes, critical thinking, and equal or above international standards. But to achieve the reform's mission, it depends on efficiency of educational management process that put school as final service outcome. The educational act also specifies in Section 29 that for educational administration schools should engage with individuals, families, communities, community organizations, local administration organizations, private agencies, professional organizations, religious institutions, business units, and others to strengthen community strength. Learning process inside community includes education and training on knowledge and information gathering, ability to access and choose wisdoms and academic disciplines for community development to fit with problems and needs and to learn ways to transfer and exchange community development experiences (The Office of the Basic Education Commission, 2013). School administrator therefore is the most significant key success factor to coordinate and preserve the balance among major players - teachers, school personnel, school board members, parents, local governments, and other government units - to make sure students are developed to achieve desirable characteristics. They are good, smart, and happy citizens who can adjust and balance with the changing world.

Therefore, knowledge management is the necessary tool for learning resources acquisition through the process of data transformation with previous experience to apply with individual and organization. The process of knowledge management increases organization efficiency in the long run with increase organization knowledge and transformation into intelligent capital (Wijan, 2010; Becerra-Fernandez, Gonzalez, \& Sabherwal, 2004; Debowski, 2006). The knowledge management needs systematic process and opens community to engage in each step in order to achieve goal. This is in line with Wijarn (2010) who summarizes that knowledge management must employ systematic participation action research in each step.

\subsection{Research Problems}

Nong Kung Wittayakarn School is a medium-sized opportunity expansion school which lacks management on internal and external learning resources necessary for learning activities on preservation and continuation of local culture into sustainable sufficiency-oriented life. The school should acquire systematic learning resources management to increase potential on learning services with engagement from stakeholders (Nong Kung Wittayakarn School, 2017). This research aimed to create systematic learning resources knowledge management in the community with participation action research method. The stakeholder groups would gain motivation, encouragement, and sense of belonging to accept the development guideline with their participation in order to get learning with researchers. The knowledge of learning resources management process in this research can be applied to individual and community in the future.

\section{Literature Review}

\subsection{Participatory Action Research}

Participatory action research (PAR) is the attempt to meet the needs of human for worthy goals. It's based on participatory principle mixed with action and reflection. PAR concepts describe characteristics of public participation that originates from solving urgent social problems (Reason \& Bradbury, 2001, Chatterton, Fuller, \& Routledge, 2007 cited in Graham \& Lawrence, 2008; \& Kemmis, McTaggart, \& Nixon, 2014; Kangpheng \& Kunlong, 2015; Paso, Chantarasombat \& Tirasiravech, 2017). Therefore, PAR is a process of studying and creating new knowledge according to research principles with the main goal of bringing the research results to solve the problem. The emphasis is on getting collaboration from all related social members to think and act together from the beginning.

\subsection{Systematic Learning Resources}

Learning resources management strategies are important component of successful academic learning. Some common and most used learning resource management strategies are management of learning time, management of study environment, effort management, peer learning, seeking assistance from qualified and significant others etc. (Ahmed \& Khanam, 2014; Pintrich, Smith, Garcia, \& McKeachie, 1991). The implementation of those strategies to achieve effective learning results need learning resources management process.

Knowledge management (KM) can be defined as a systematic and integrative process of coordinating the organization-wide activities to define, retrieve, use, share, create and store knowledge, actionable information and 
expertise of individuals and groups in pursuit of organizational goals (Cheng 2012, 2015; Pandey, 2016). These KM processes support organizational processes involving innovation, individual learning, collective learning and collaborative decision making. KM enables the maximization of organizational knowledge-related effectiveness and prosperity and provides a sustainable competitive advantage (Wiig 2004; Hatch \& Dyer 2004; Pandey, 2016). KM supports organizations in creating a mechanism that measures, stores and transforms knowledge into intellectual capital. It increases the capability of staff to solve problems and the ability of the organization to make improvements (Sallis \& Jones 2002).

Applying KM in school education is a new concept; thus, we need a KM model to help us conceptualize the disparate elements of the complete picture in a way that leads to a deeper understanding of how the knowledge process works within the school organization. For example, it is important to have a solid foundation of understanding about what $\mathrm{KM}$ is, what the key $\mathrm{KM}$ cycle processes are, and how these processes feed into a model, in order to interpret and set up a causal relationship. (Change, 2015; North \& Kumta, 2018)

However, all the different views give similar processes of planning, organizing, motivating and covering work activities in an organization to guarantee improvement efficiently and success. The main process includes the action to Define, Create, Capture, Share and Use.

\section{Objective}

The research objective was to develop and evaluate systematic learning resources management process in inputs, process, outputs, outcome and feedback of elementary school.

\section{Research Method}

The researchers followed the participatory action research (PAR) of Kangpheng and Kunlong (2015); Paso, Chantarasombat and Tirasiravech (2017) adapted from Critical Participatory Action Research of Kemmis, McTaggart, and Nixon (2014). The study was performed during 2017 school year (May 16, 2017 - April 30, 2018) with 2 circles of PAR each circle in one school semester at Nong Kung Wittayakarn School, Khon Kaen, Thailand. The study had three phases.

\subsection{Research Participants and Key Informant Group}

Research participants and key informant group included 5 secondary Grade 7-9 level teachers, 34 students in those levels, 34 student parents, 9 school board members totaling 82 people. The participants were selected by purposive sampling from schools with similar context and problems required to meet the research objectives.

\subsection{Variables Study}

Variables studied were systematic learning resources management comprising inputs, process, outputs, outcome, and feedback.

\subsection{Research Stages}

\subsubsection{Preparing}

This primary data survey phase included knowledge management, internal/external learning resources, and knowledge management process comprising inputs, process, outputs, outcome, and feedback. Research tools were;

1) Checklist form,

2) Semi-structured interview form,

3) General meeting record form.

Data analysis employed frequency and percentage statistics together with content analysis.

\subsubsection{Doing}

This included the following;

\section{1) Reconnaissance}

This comprised opening communicative space, dialogues between system and life world, strategic action and communicative action, questions to identify a shared felt concern in relation to our practices and what holds our practices, and an initial statement about what you intend to do.

2) Planning

This comprised changing practices and practice architectures, and the product of planning - a collective rationale and plan for change. 
3) Reflection;

This comprised spiral cycles of self-reflection.

\subsubsection{Evaluating}

The evaluation of the entire model was conducted with 5 level assessments (Guskey, 2016). The question items were participants' reaction, participants' learning, organization support and change, participants' use of new knowledge and skills, and participants' satisfaction.

\subsection{Data Collection and Analysis}

Research tools were questionnaires form, semi-structured interview form, and meeting record form. The data were analyzed by statistics of mean $(\overline{\mathrm{X}})$, and standard deviation $(\mathrm{SD})$ together with content analysis.

\section{Conclusion and Discussion}

\subsection{Conclusion}

Systematic learning resources knowledge management process development comprised the activities as the following:

1) Inputs including personal wisdom or resources as enduring virtues, personal knowledge, and internal external personnel.

2) Process including Define-identifying types of intelligent capital or desired knowledge; Create-fostering intelligent capital or utilizing existing resources, supplementary external study, learning others' successes, benchmarking, and collecting documents, data, knowledge according to interested group. Capture-systematically seeking and store knowledge in the forms of documents, data files, CDs and websites; Share-sharing and exchanging learning, distribution, and learning transformation; and Use - utilizing or applying then knowledge in daily life.

3) Outputs overall findings indicate 3.33 average point from the 4-point scale with people having highest score, followed in descending order as economic, societal, environmental and cultural domains.

4) Outcome the findings indicate the sufficiency-oriented life satisfaction in overall and detailed categories are at high level with psychological dimension having highest score, followed in descending order as well-being sustainability-self-reliance, immunity, and resilience.

5) Feedback the systematic learning resources management process with reflection cycle include before action review (BAR), during action review (DAR), and after action review: AAR) as shown in Figure 1.

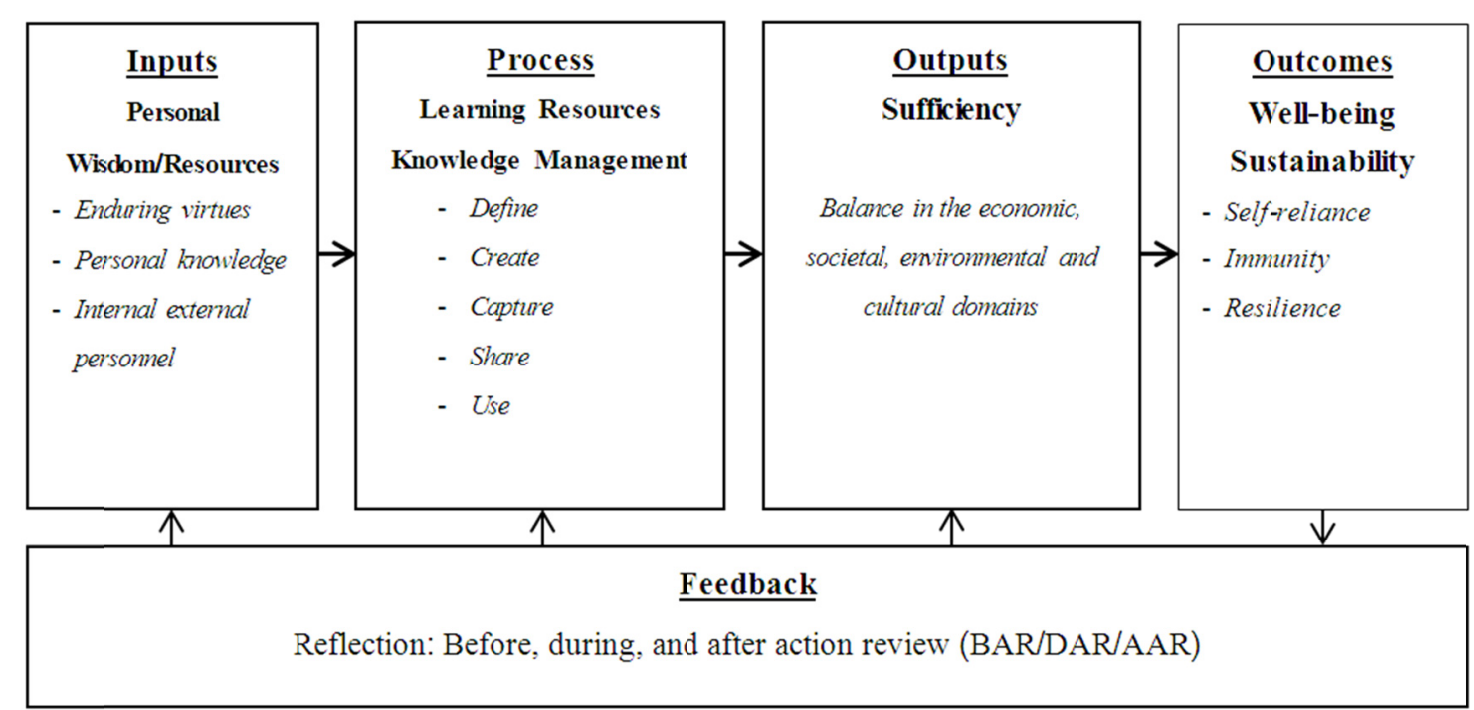

Figure 1. Systematic learning resources management process to strengthen sufficiency attributes

6) The evaluation of systematic learning resources knowledge management process reveals that the participants' acceptance is at highest level ( $\overline{\mathrm{X}}=4.613, \mathrm{SD}=0.792)$, participants' learning is at highest level $(\overline{\mathrm{X}}=4.512, \mathrm{SD}=$ $0.881)$, organization support and change is at highest level $(\overline{\mathrm{X}}=4.663, \mathrm{SD}=0.733)$, participants' use of knowledge 
or skill is at highest level $(\overline{\mathrm{X}}=4.724, \mathrm{SD}=0.817)$, and participants' satisfaction is at highest level $(\overline{\mathrm{X}}=4.534, \mathrm{SD}$ $=0.737)$ as shown in Table 1 .

Table 1. Evaluation of systematic learning resources knowledge management process

\begin{tabular}{llll}
\hline Variables & Mean $(\overline{\mathrm{X}})$ & Std. (SD) & Level \\
\hline Participants' acceptance & 4.613 & 0.792 & highest \\
Participants' learning & 4.512 & 0.881 & highest \\
Organization support and change & 4.663 & 0.733 & highest \\
Participants' use of knowledge & 4.724 & 0.817 & highest \\
Participants' satisfaction & 4.534 & 0.737 & highest \\
\hline
\end{tabular}

However, the key point the researchers learned beyond the research objectives was creating Community of Practice in school. The researches and stakeholders held many meeting for knowledge exchange and learning continuously. The new knowledge has been applied to activities for effectiveness.

\subsection{Discussion}

The systematic learning resources management process includes 1) Define-identifying desirable body of knowledge; 2) Benchmark/Create - creating intelligent capital, knowledge, benchmarking; 3) Capture - seeking and storing body of knowledge; 4) Share - sharing, exchanging, disseminating and transferring of knowledge; and 5 Use-utilizing and/or implementing knowledge. From this study and from this study's literature review and empirical data collection and analysis with survey, interview, and meetings with related participants give congruent conclusion as the following. The first important point is that of identifying desirable intelligent capital or body of knowledge. Since intelligent capital or body of knowledge in any community exist in various types and forms. It is necessary to know and understand those to serve the needs and solve problems for each community. The understanding of the past, present, and future of a community enable for suitable planning to solve problems. The lack of standing or knowing only separate parts of the context not only results in failure but worsen the situation. This conclusion is in line with the findings of other academics. Probst, Raub, and Romhardt (2000) stated factors of knowledge management process. They are 1) knowledge identification for knowing learning resources and pattern of knowledge in organization; 2) knowledge acquisition for seeking and selecting external knowledge sources; 3) knowledge development for utilizing acquired knowledge in suitable form for organization management; 4) knowledge transfer for others to work and creating new knowledge among individuals, groups, and organization; 5) knowledge utilization for efficient application in organization; and 6) knowledge storage for sharing and re-use in the future.

Besides, Srikantaiah and Koenig (2000) point out that organization needs discipline in knowledge management process for effective results. They are capturing, evaluating, sharing, and information assets storing on knowledge management in the database and in organization policy. Tannonbaum and Alliger (2000) offer 4 principal approaches for efficient knowledge management. They are knowledge sharing, knowledge accessibility, knowledge assimilation, and knowledge application. Moreover, Kucza (2001) state 6 factors of operational knowledge management process. They are identification of need for knowledge, knowledge pull, knowledge push, knowledge creation, knowledge collection and storage, and knowledge update. Wiig (2004) also gives factors for knowledge management process in continuous cycle as knowledge acquisition, knowledge storage and retrieval, knowledge usage/utilization, knowledge transfer/distribution/ sharing, and new knowledge creation. Wijarn (2010) also give 5 steps of knowledge management as defining type of knowledge, creating intelligent capital, capturing and storing knowledge in organization systematically, sharing knowledge, and using knowledge.

The Thailand Productivity Institute (2005) views knowledge management process as a tool to help organization understand how to develop knowledge within organization. There are 7 steps including knowledge identification, knowledge creation and acquisition, knowledge organization, knowledge codification and refinement, knowledge access, knowledge sharing, and learning, and Cheng (2012, 2015); Pandey (2016) knowledge management can be defined as a systematic and integrative process of coordinating the organization-wide activities to define, retrieve, use, share, create and store knowledge, actionable information and expertise of individuals and groups in pursuit of organizational goals. So these KM processes support organizational processes involving innovation, individual learning, collective learning and collaborative decision making. KM enables the maximisation of organizational knowledge-related effectiveness and prosperity and provides a sustainable 
competitive advantage (Wiig 2004; Hatch \& Dyer 2004; Pandey, 2016).

Therefore, the research findings indicate that systematic learning resources management process can be applied suitably to develop learning resources on local culture learning resources and conservation for sufficiency-oriented life quality. The process can also be utilized in other areas of development depending on the problems and needs of the community. The significant success factor index is to create and develop group awareness among teachers and stakeholders. At the same time for the sustainability of this effort there should be training of major responsible teachers to learn and understand the process well with systematic continuous cycle to become supplementary occupation with income for teachers and students.

\section{Suggestion}

\subsection{Suggestion for Research Application}

1) The school should define clear and continuous policy on learning resources management. The other bodies of knowledge can be included such as knowledge management on network promoting education innovation for teachers or STEM study.

2) Schools' superior agency should arrange knowledge management training on other disciplines such as learning resources on Sufficiency Economy Principle, Professional Learning Community (PLC), or research for learning innovation development.

3) There should be systematic learning resources management centers in schools with modern equipment for searching knowledge such as computer, high speed internet.

4) There should be encouragement for teachers to apply learning resources management process in class with continuous evaluation of results.

\subsection{Suggestions for Further Research}

1) This research employed participatory action research (PAR) with limited generalization due to targeted schools and specific context. Further research should be on research and development on model of systematic learning resources management on other topics or contexts.

2) This research was on learning resources management on cultural preservation and continuation of local community for sustainable sufficiency-oriented on magical germinated rice for health which is suitable to the needs in specific locality. The research method can be applied to other topics according to specific problems and needs of other locality.

3) There should be expansion of systematic learning resources management in other schools with similar context or widely in other groups of school.

\section{References}

Ahmed, O., \& Khanam, M. (2014). Learning Resources Management Strategies and Academic Achievement of Secondary School Students. The International Journal of Indian Psychology, 2, 2348-5396.

Becerra-Fernandez, I., Gonzalez, A., \& Sabherwal, R. (2004). Knowledge management: Challenges, solutions, and technologies. New Jersey: Pearson Prentice-Hall.

Cheng, E. C. K. (2012). Knowledge strategies for enhancing school learning capacity. International Journal of Education Management, 26(6), 557-592. https://doi.org/10.1108/09513541211251406

Cheng, E. C. K. (2015). Knowledge management for school education. https://doi.org/10.1007/978-981-287-233-3

Guskey, T. R. (2016). Gauge impact with 5 levels of data. Journal of Staff Development, 37(1), 32-37. Retrieved from http://tguskey.com/wp-content/uploads/Professional-Learning-1-Gauge-Impact-with-Five-Levels-ofData.pdf

Hatch, N. W., \& Dyer, J. H. (2004). Human capital and learning as a source of sustainable competitive advantage. Strategic Management Journal, 25(12), 1155-1178. https://doi.org/10.1002/smj.421

Kangpheng, S., \& Kunlong, S. (2015). Participatory action research (Maha Sarakham: The Degree of Doctor of Philosophy in Educational Management for Local Development, Rajabhat Maha Sarakham University).

Kemmis, S., McTaggart, R., \& Nixon, R. (2014). The action research planner: Doing critical participatory action research. https://doi.org/10.1007/978-981-4560-67-2

King, W. R. (2009). Knowledge management and organizational learning. Graduate School of Business, 
University of Pittsburgh. https://doi.org/10.1007/978-1-4419-0011-1

Kucza, T. (2001). Knowledge management process model. Retrieved from http://www.Inf.vtt.f/pdf/publication/2001/p.455.pdf

Local Administration Organization, Northwestern Provinces Group. (2014). A framework for lifelong learning management: Aiming at local professional excellence. Kalasin: Local Administration Organization.

Nong Kung Wittayakarn School. (2017). Self-assessment Report: 2016 Academic year. Maha Sarakham: Apichart Printing.

North, K., \& Kumta, G. (2018). Knowledge management: Value creation through organizational learning (2nd ed.). https://doi.org/10.1007/978-3-319-59978-6

Pandey, K. N. (2016). Paradigms of knowledge management with systems modelling case studies. https://doi.org/10.1007/978-81-322-2785-4

Panich, V. (2015). Knowledge management. Retrieved from http://huahin.dusit.ac.th/bg/KM/KM_Article.pdf

Paso, C., Chantarasombat, C., \& Tirasiravech, W. (2017). Strengthening teacher's learning management for self-reliance of students in Thai secondary school. International Education Studies, 10(3), 165-175. https://doi.org/10.5539/ies.v10n3p165

Pintrich, P. R., Smith, D., Garcia, T., \& McKeachie, W. (1991). A manual for the use of the motivated strategies for learning questionnaire (MSLQ). Ann Arbor, MI: University of Michigan, National Center for Research to Improve Postsecondary Teaching and Learning.

Probst, G., Raub, S., \& Romhardt, K. (2000). Managing knowledge: Building blocks for success. England: John Willey \& Sons.

Sallis, E., \& Jones, G. (2002). Knowledge management in education: Enhancing learning and education. London: Kogan Page.

Shelda, D. (2006). Knowledge management. New Jersey: Pearson Education, Inc.

Srikantaiah, T. K., \& Koenig, M. E. D. (2002). Book Review: Knowledge management for information professional. New Jersey: Information Today.

Tannonbaum, S. I., \& Alliger, G. M. (2000). Knowledge management: Clarifying the key issue. U.S.A.: the International Association for Human Resource Information Management.

Thailand Productivity Institute. (2005). Knowledge management from theory to practice. Bangkok: SE-EDUCATION.

The Office of the Basic Education Commission. (2013). Student support system for improving the quality of life, and solve the social crisis, the path to professional teachers. Bangkok: Chuanpim Printing.

Wiig, K. M. (2004). People-focused knowledge management: How effective decision making leads to corporate success. Amsterdam: Elsevier Butterworth Heinemann.

Wijarn, B. (2010). Development of learning organization (7th ed.). Bangkok: Expernet.

\section{Copyrights}

Copyright for this article is retained by the author(s), with first publication rights granted to the journal.

This is an open-access article distributed under the terms and conditions of the Creative Commons Attribution license (http://creativecommons.org/licenses/by/4.0/). 